\title{
EXISTENCE OF THE COMMUNITIES IN HISTORIC AYUTTHAYA TOWN, THAILAND
}

\section{Tapanee Rattanathavorn ${ }^{1}$ Khaisri Paksukcharern ${ }^{2}$ Wannasilpa Peerapun ${ }^{3}$}

\begin{abstract}
This article analyzes the relationship between the spatial configuration and socio-economic factors to find the existence of the communities in the historical city of Phra Nakorn Sri Ayutthaya, an island area mainly covered with historical monuments. This area has historical structures covering most of the town, so the communities here at present are small. The transportation network in the area is not systematically connected to the town itself and, thus, cannot serve a wide-range of community activities. The activities that do take place are not spread evenly across the area according to its integration value. As a consequence, communities cannot be self-reliant but instead are cross-community reliant and
\end{abstract}

\footnotetext{
${ }^{1}$ Ph.D. Candidate, Department of Urban and Regional Planning, Faculty of Architecture, Chulalongkorn University, Bangkok, Thailand

${ }^{2}$ Assistant Professor of Urban and Regional Planning, Department of Urban and Regional Planning, Faculty of Architecture, Chulalongkorn University

${ }^{3}$ Associate Professor of Urban and Regional Planning, Department of Urban and Regional Planning, Faculty of Architecture,

Chulalongkorn University

Please visit

http://www.manusya.journals.chula.ac.th/html/ search. for a colored version
}

depend on the development of certain relationships to maintain their existence.

The research process for the study includes data collection regarding socioeconomic activities for joint analysis using a spatial model created with a geographical information system. The research results reveal that these communities coexist as a "community group" of which there are three types: namely 1) a community group with a complete set of necessary elements that allow it to exist as a group, for example, "Huaro Market community group" and "Chaophrom Market community group," 2) a community group that does not have all the necessary elements and only needs to rely on other communities occasionally, for example, "Pratoochai community group" and "Pakkran-Banpom community group," and 3) a community group that does not have complete elements and always needs to rely on other communities both near and far, for example, "Rongngansura community group." The nature of the three community groups is reflected in the difference in efficiency of the level of the transportation network in the area, which is a result of the confining arrangement of the historical structures in the area.

This research thus sees the major factor in the continued existence of the communities in the historic town as the preservation, enhancement, and rehabilitation of the transportation network so that it appropriately connects the communities in the area of historical structures in a way that benefits each community group. This will allow for greater integration and foster $a$ variety of activities as complementary elements of the communities while letting them retain their own identity. 


\section{Introduction}

Phra Nakorn Sri Ayutthaya is a town situated in the Chaophraya River delta in the central region of Thailand. During the period of $19^{\text {th }}-21^{\text {st }}$ Buddhist centuries, it prospered and became the capital of the Kingdom of Siam, bearing the name of Ayutthaya or "Judea" (The Fine Arts Department 1997: 1; Kasetsiri 2007: 20) (Figure 1). Town development in the past gave the area a geomorphological structure that made it into an 'island', as it is surrounded by three rivers (the Chaophraya, the Pasak, and the Lopburi). At present, this area supports a large community that has experienced over 600 years of development. It thus has historical importance and contains historical structures consisting of temples, forts, town walls, ancient roads, canals and moats as well as other ancient structures covering a total area of 3,200 rai or about $70 \%$ of the town (Calculated from Geo-information system data, Researcher 2010), with some of the historical structures being under the care of the Department of Fine Arts. The area is thus designated as off limits and public events cannot be held there without permission. Over time, a number of communities have sprung up in the limited spaces among the historical structures, buildings and along the riverbanks. These communities cannot expand freely like most other communities, however, became the historical structures form spatial enclaves or urban barriers. Smailes (1966) refers to such spaces as enclaves of relict morphological units as there has been little or no change in them resulting from regular urban socioeconomic influences.

Due to the presence of historical structures in the area of the Historic Town of Phra Nakorn Sri Ayutthaya, the settlement's morphology is that of small communities with limited space for social activities. In addition, these historical structures obstruct the transportation system in the communities and the town in general. People cannot circulate freely in the area and activity cannot spread out in line with the area's potential. Many activities are thus confined to less restricted such as trade at Chaophrom Market and Huaro Market. These markets would normally be located in the heart of the town but have been forced into areas further away from the communities. Also, other activities are clustered in an area east of town, while in the communities themselves, in general, there is only space for limited social interaction and small trade. Some communities may have religious structures in which to carry out ceremonies or multipurpose public spaces. However, no community has adequate space for the full-range of activities common to most typical communities. (Field surveying data by the author, 2010) (Figure 2-3) 

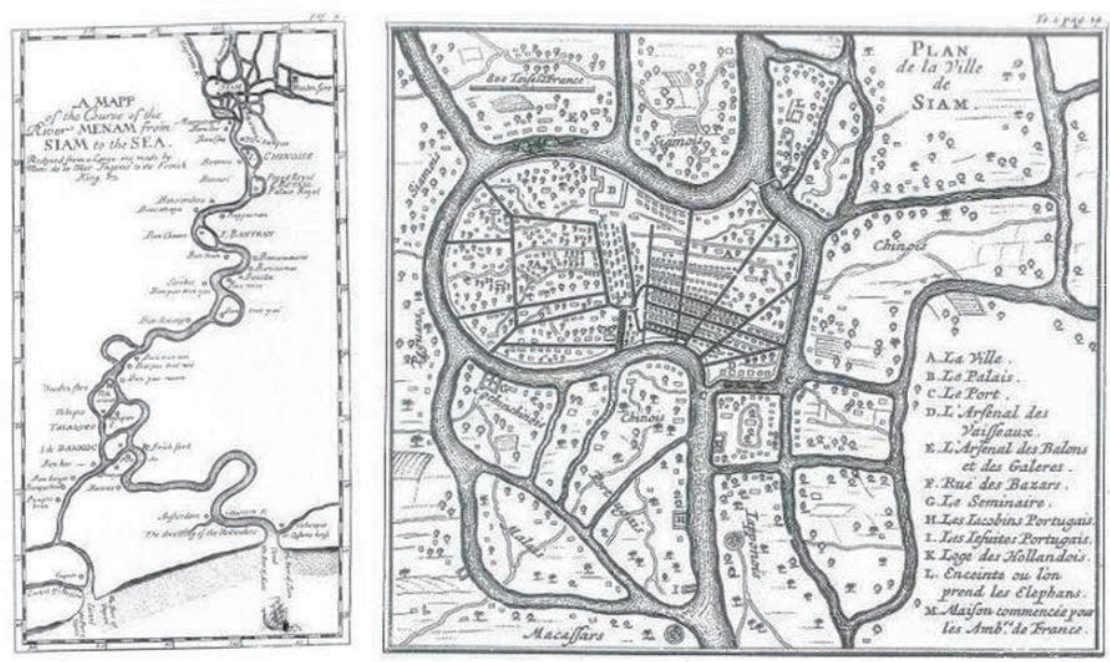

Figure 1: Drawing of the Historic Town Area of Phra Nakorn Sri Ayutthaya as it appears in French diplomat de La Loubere's annals (cited in Tangsiriwanit 2006).
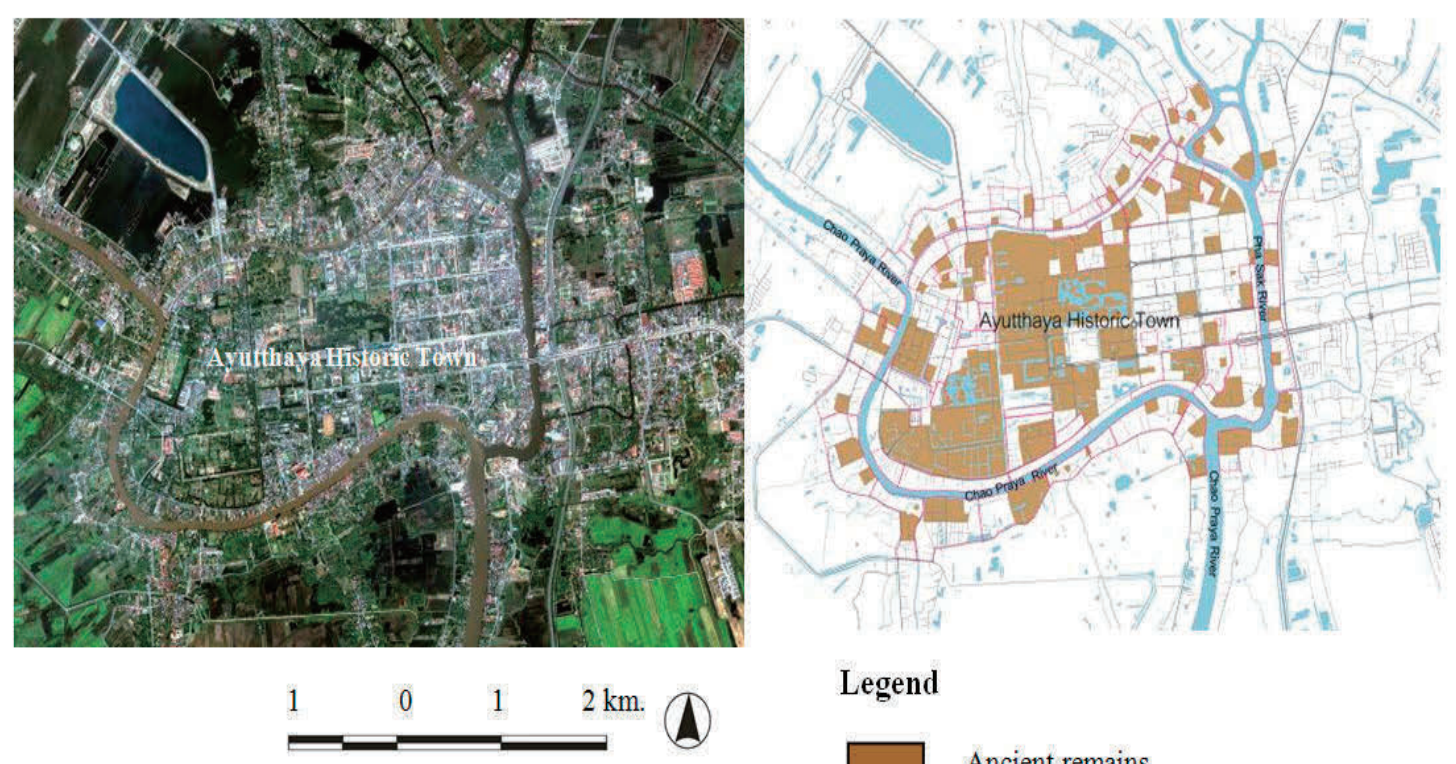

Legend

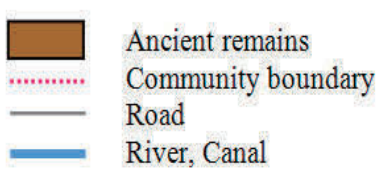

Figure 2: The morphological features of the Historic Town of Phra Nakorn Sri Ayutthaya Figure 3: The positions of historical structures and community boundaries (devised by the author, 2010) 

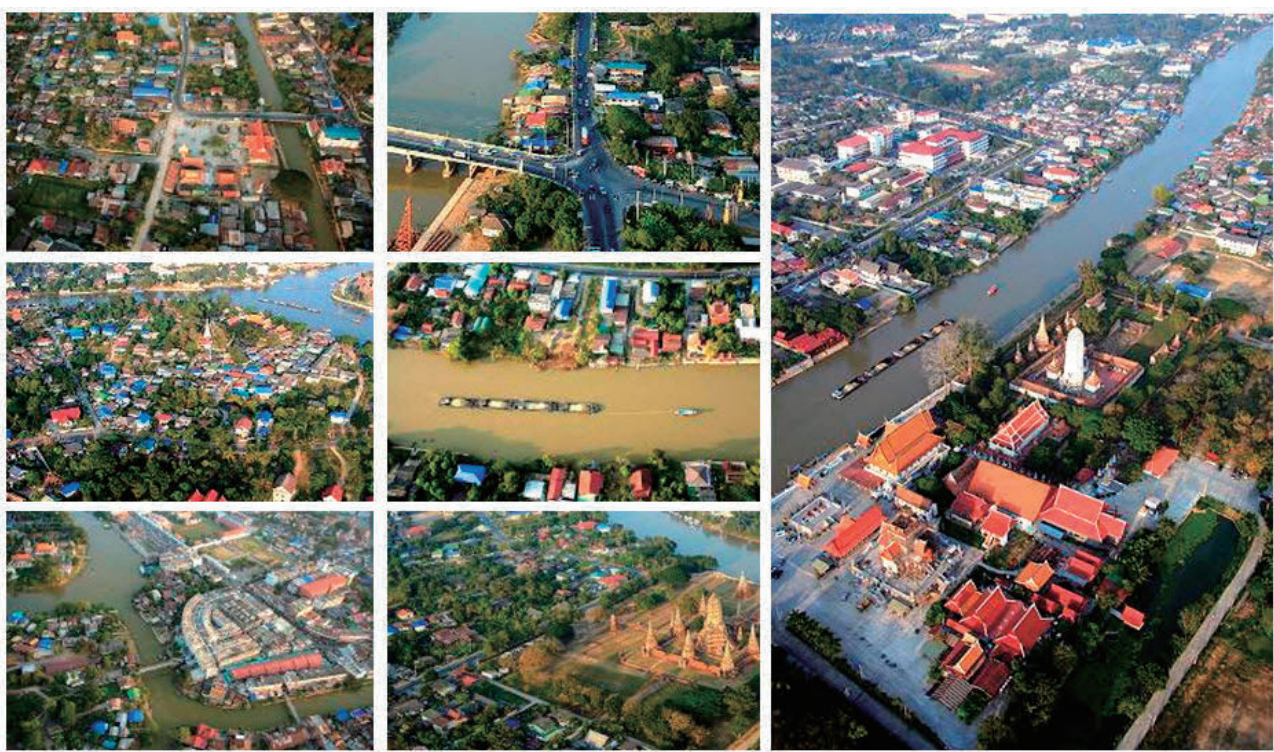

Figure 4: Featured communities and historical structures in the Historic Town of Phra Nakorn Sri Ayutthaya

For these reasons, people in the various communities must travel to different communities to conduct certain necessary activities and, in this way, communities help support each other. Hillier and Hanson (1984) see this network of socioeconomic activity occurring across communities as providing people with channels and opportunities for social survival (Suwan-Achariya 2006: 11; Satyawadhna et al. 2004: 61). These people choose to conduct activities or to be part of a network based on familiarity, beliefs, customs, traditions, rules or agreements that have developed over time (Khanjanusathiti 2009: 126). These may involve activities of which those involved have a collective memory based on the long-standing social identity of the community (Phatumanonta 2000). People in some communities conduct certain activities in their own neighborhood but those in others may need to go further away depending on the morphological features of the community itself as well as the socio-economic and cultural characteristics of the people in the community.

The existence of communities is thus related to the morphological structure, which reflects and relates to people's social lives (Hillier and Hanson 1984). Transportation is a major morphological element since most people use it in their daily lives and it allows for a diversity of activities which, in turn, makes the town lively and provides a pleasant atmosphere and good quality of life for the inhabitants (Jacobs 1961). A good and efficientlyconnected transportation network makes it possible for both inhabitants and visitors, who have different purposes and destinations, to get to the area as well as move through to other places conveniently (Hillier and Hanson 1984). An efficient 
network promotes diverse socio-economic activities which can spread out according to their integration value (Hillier et al. 1993). As people's natural movement may be at a high or low level based on the connectivity of the area's network, some areas may be quiet while others are bustling, causing an uneven spread of activities under the movement economy process (Hillier 1996). Activities requiring quiet, such as residential activities, religious activities, etc., tend to cluster in areas with a low integration value while activities involving a lot of people or traffic, such as trade, tend to concentrate in areas with a high integration value, which in turn serves as an attractor, multiplying the effect. As a result, the area develops a transportation network with grid intensification and more intensive activity than other areas. Such an area becomes busy and commercial along with other areas which have activities spreading out naturally. This is a characteristic of a lively town center incorporating spatial centrality as a process (Hillier 2000). It is an important feature of urban morphology which allows a community to exist in a sustainable manner.

With limitations in terms of morphology and certain socio-economic and cultural factors, these communities have developed distinct characteristics. It would be useful to examine the characteristics of such communities, as well as the various influencing factors, as the body of knowledge gained will be beneficial in planning for the preservation or rehabilitation of the communities allowing them to continue into the future while retaining their individual characteristics. This research, thus, has the following objectives: 1) to analyse the morphological features of the area, the socio-economic and cultural characteristics, as well as external factors relating to the existence of communities in this historic town area, and 2) to analyse the patterns of relationships that various communities have with each other and those that they have with the town as a whole that enable them to function.

\section{Methodology}

The study relies mainly on spatial configuration analysis as the main research tool in conjunction with analysis of activities which reflect the building and land use patterns as follows:

\section{Spatial configuration analysis}

Spatial configuration analysis is the analysis of the morphological features of community areas and towns according to the concept of urban morphology presented by Hillier and Hanson (1984). The concept states that the nature of the connectivity of transportation routes is always related to the level and the popularity of transportation in the community or town. People tend to choose to travel along the most direct and the shortest routes. Therefore, people's transportation is modeled visually as axial lines, "the longest lines of sight and access" through open space crossing transportation routes of the community or the town (Figure 5a) that are connected into convex spaces (Figure $5 b$ ). These are represented by the longest lines in the smallest number which connect to each other throughout the system. This is called an axial map or a spatial configuration model of the community area or town (Figure 5c). 


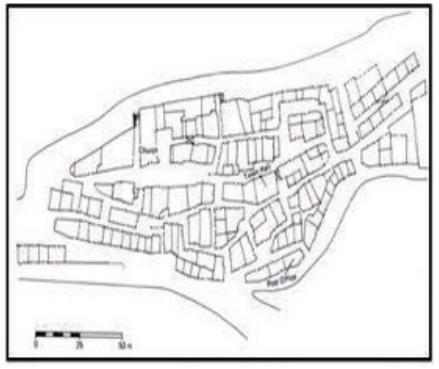

(a) Road pattern for analysis in Gassin, France

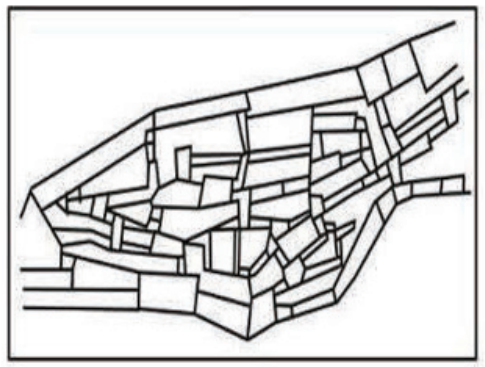

(b) Convex spaces

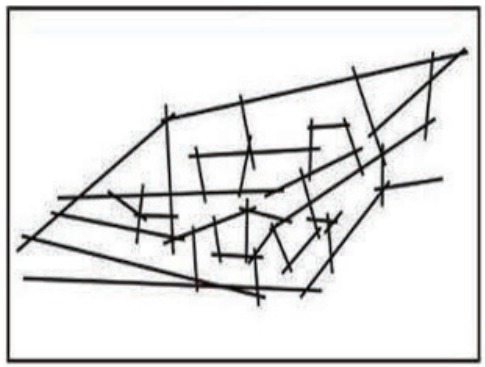

(c) Axial map

Figure 5: Creating a spatial configuration model (Hillier 1996)

After this, Space Syntax (Tuner et al. 2005), a spatial analysis program tool, was used to study the integration value of the various routes in the network. Then the routes with the highest integration value, being more integrated into the town than other areas, were determined and are represented by red lines, followed by orange, yellow, green, and light blue as in the spectrum. Meanwhile, those with the lowest integration value, or showing segregation from the town in general, are represented in blue, reflecting that they tend to be little used.

The analysis results of the spatial configuration model of a town in general should show lines of all colors (from red to blue), which means that the transportation network of the town consists of routes with different integration values, from high to low, depending on the connectivity of the network itself. An area with hot color lines means that the transportation network in that area has a high integration value, so there is a tendency for people travel around in this area more than in others. Mostly, such areas are commercial or areas of other social activity. On the other hand, areas with cool color lines mean that the transportation network in that area has a low integration value, so there is a tendency for people to travel in that area less than in others. This kind of area is mostly used for residential purposes or for activities that require quiet. Activities should happen in an area of town in accordance with its integration value, which is an important characteristic of good spatiality according to Hillier (2000).

Space syntax was used to analyze the area to determine and ensure the accessibility potential of the overall transportation network and also to systematically analyze each separate route. In addition, the analyzed results were compared in order to further the understanding of community "spatial centrality as a process". When the results are considered using socioeconomic analysis, they appear, logically, to support the existence of the community.

\section{Socio-economic analysis}

Socio-economic analysis looked at the social, cultural and economic aspects of the area using the geographic information system (GIS) to analyse the levels of 
building use and land use based on the same area boundary as in the spatial configuration analysis. Questionnaires were also used to acquire information regarding local people's social, cultural and economic activities. The questions addressed type, frequency and venue of activities. The respondents were to be the heads of households or their wives. A total of 9,154 households in 62 communities were given one questionnaire each. The questionnaire was administered using Taro Yamane's sampling selection at the $95 \%$ confidence level. A total of 384 sets of questionnaires were completed by the random sampling group of 384 households. The data was collected during the period from July to December 2011 and it was then sorted and activities categorized. The locations where the activities were conducted were plotted on a "social map" using colored dots.

The social map of a typical community should show a diversity of activities, such as trade or socializing, in high activity areas, and residential and religious activities in quieter areas. This shows that people in the community or town are conducting a full range of normal community activities. Both the spatial model and the social map should reflect that the activities and land use correspond appropriately. In other words, those activities requiring quiet should be on routes with a low integration value (cool color lines) while more intensive activities should be on routes with a high integration value (hot color lines). This is an important condition that contributes to community sustainability. On the other hand, community areas or towns that do not show the full range of colors or where activities do not correspond to the integration value of the area may have certain unbalanced social conditions which would require additional analysis by way of questionnaires completed by local people to identify.

\section{Study Results}

\section{Spatial configuration characteristic}

To study the spatial configuration of the communities of the Historic Town of Phra Nakorn Sri Ayutthaya, a spatial model was created using the geographic information system (GIS), with a road network layer, waterway layer and open space. The spatial model of Historic Ayutthaya Town covers an area of about eight square kilometers $(15,000$ rai), stretching to the AH1 Highway in the east and, then, along the highway in a northerly direction and extending to state highway \# 347 in the west and state highway \# 356 in the south. To ensure that the data regarding transportation routes within the area was current and still in use, the study area of both Ayutthaya town and the communities around the historic island area was surveyed (July-December 2011). The model depicts roads, side streets, alleys, walkways, shortcuts, open areas and temple grounds. It also shows rivers and streams as well as linking points such as bridges and ferry piers that the public can use freely. 


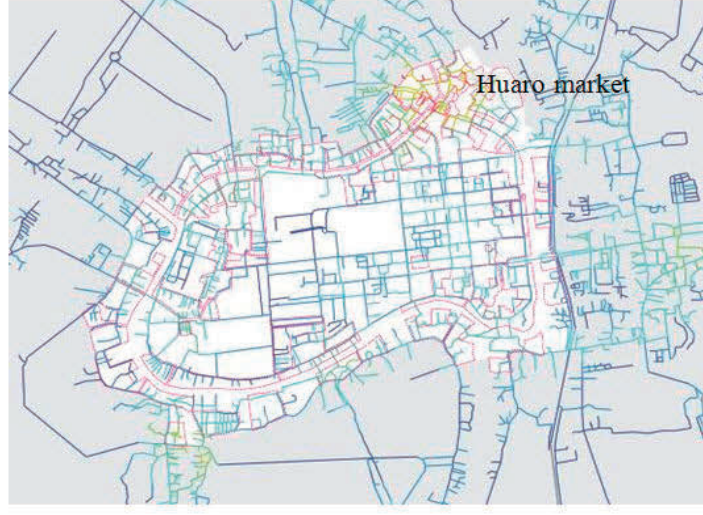

(a) Move-to transportation potential

Legend

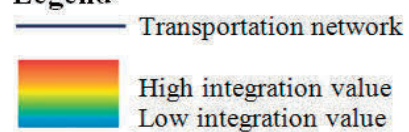

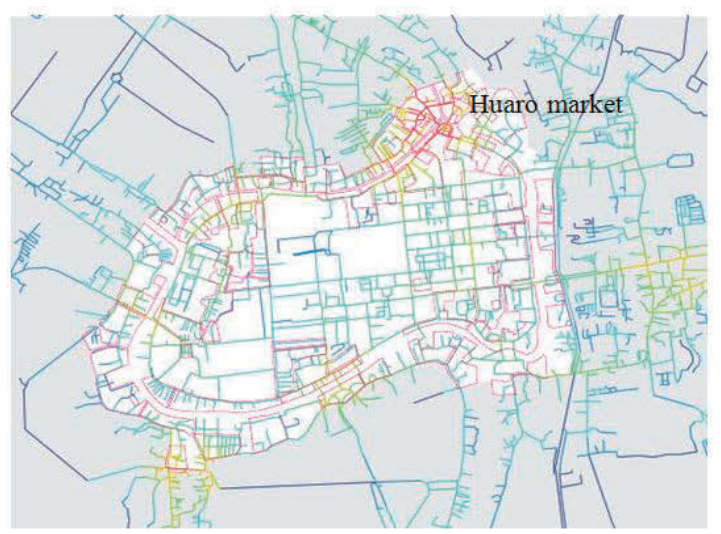

(b) Move-through transportation potential

Figure 6: The spatial model of the Historic Town of Phra Nakorn Sri Ayutthaya

\section{Socio-economic characteristic}

To study the socio-economic factors of communities in Historic Ayutthaya Town, a social map was created using the geographic information system (GIS) with levels of building and land use information based on the same area boundary as in the spatial configuration analysis. This was combined with an analysis of the questionnaires completed by people in the community. It was found that there are two types of activities: permanent and temporary. The activities are determined by the government or by the local people forming groups themselves. There are three levels of activities: the community level, meaning those conducted by people in the community using the space together without involving other communities; the locality level, meaning these conducted by people from various communities using the space together due to their being close or familiar with each other or sharing beliefs or personal preferences, etc.; and the town level, meaning conducted by people from almost all communities using the space for activities, which are often determined by the government in the form of public utilities services. Activities can be grouped into nine subcategories: residential, social, handicraft and goods production, trade, change of transformation mode, religious, traditional and festival, educational, governmental and medical, and sports and recreational.

The results of the analysis of socioeconomic characteristics based on the social map at the community, locality and town levels (Figure 7) show that the major town level activities are trade (at Huaro Market and Chaophrom Market), governmental and medical (Municipality Office and Public Health Office), educational (colleges and schools), and 
change of transformation mode (bus terminal, ferry piers and railway station). Locality level activities are handicraft and goods production (weaving palm leaves into pla-tapian or fish mobiles, making candy floss, and stone carving), religious, traditional and festival, change of transportation mode (ferry piers), educational (primary and secondary schools), as well as medical and nursing (at the government medical service units and hospitals). Finally, community level activities are socializing (relaxing in the open area within the community), trade (convenience stores in the community), governmental (at community leaders' homes), and religious, traditional and festival (temples, mosques, or sacred areas in the community).

In terms of land use, over $70 \%$ of the town area is taken up by historical structures, especially the heart of the town that is designated as 'the historic town of Ayutthaya' for the purpose of the conservation of major historical structures. The area thus cannot be developed within the center of other typical towns and activities can take place in certain designated areas only. The town's plans and policies concentrate development in the east of the historic island within specific regulations. As a result, various activities such as trade, governmental, educational and residential activities are more densely concentrated in this area than in other parts of the town. Inside the historic town, there is no residential area and there are only a very limited number of social activities that take place (Figure 8). In addition, as socio-economic activities are concentrated only in certain parts of the town, people in the community must often conduct these types of activities in different areas: i.e. in their own community or in other communities either near or far. People travel outside their community for activities once or twice a week on average - mostly for shopping purposes at Huaro Market and Chaophrom Market and for medical services at hospitals.

\section{The Correlation between the spatial configurations and Socio-economic characteristics}

Using overlay mapping of the spatial model and the social map (Figure 8) to determine the integration value and activities happening in the area along transportation routes, it was found that there are four important patterns as described below (Figure 9). 


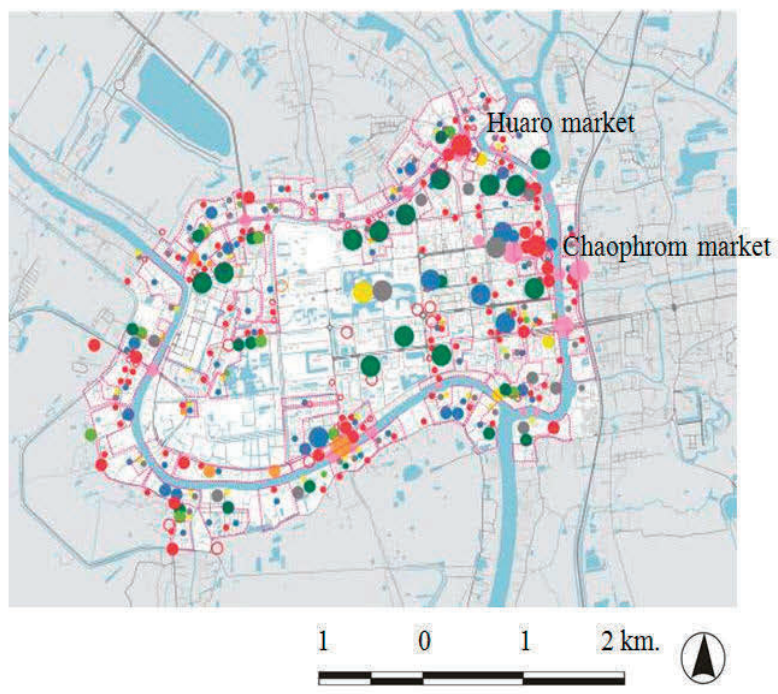

\section{Legend}

Road
River, Canal
Permanent activity
Temporary activity
Community level
Town level
Socializing activity
Handicraft and goods production activity
Trading activity
Change of transportation mode activity
Religious, traditional and festival activity
Educational activity
Governmental and medical activity
Recreation activity

Figure 7: Community boundary and social map

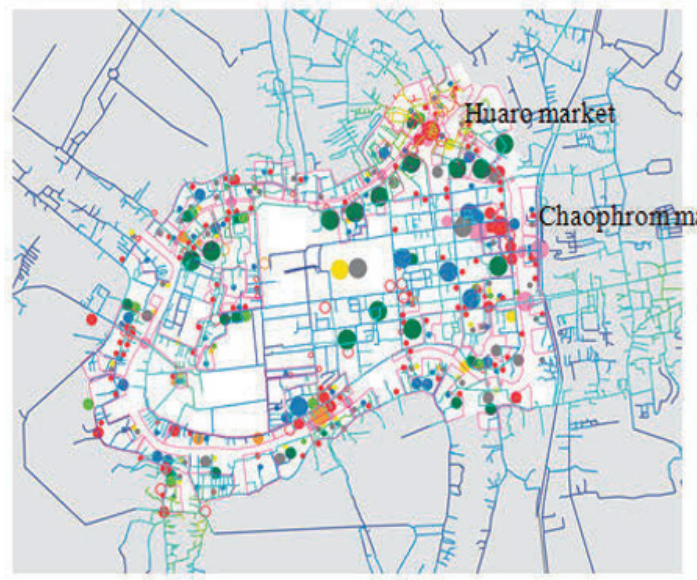

(a) Move-to transportation potential

Legend

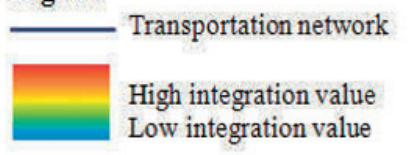

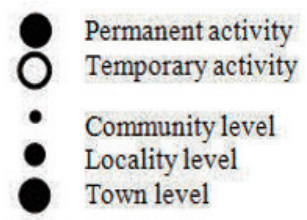

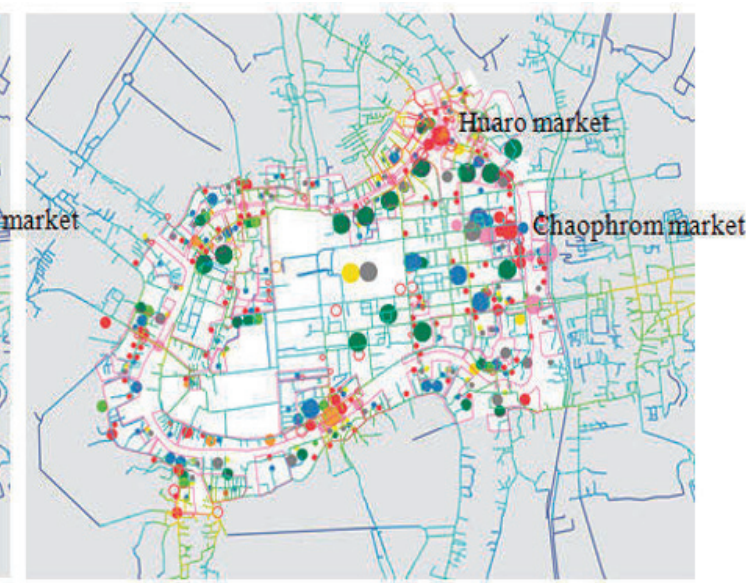

(b) Move-through transportation potential 


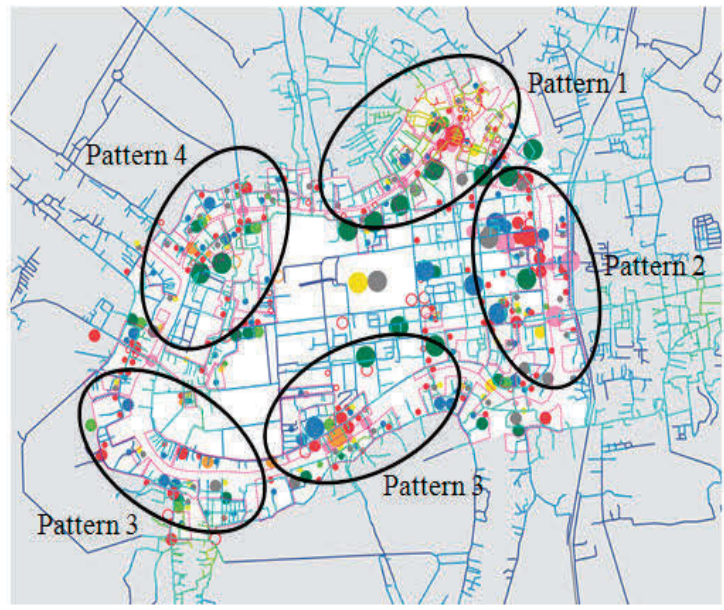

(a) Move-to transportation potential

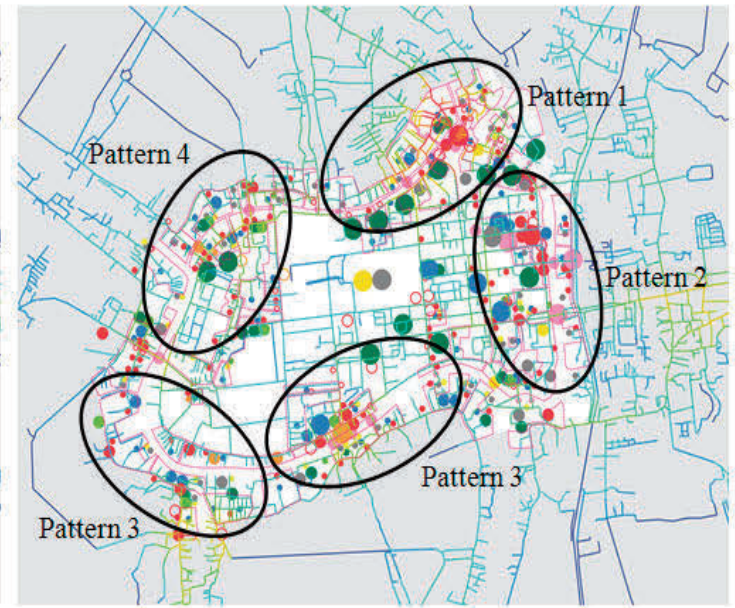

(b) Move-through transportation potential

Figure 9: The spatial features and related social, cultural and economic activities in five areas

Pattern 1: This is an area in which the spatial model shows the transportation routes of communities in hot colors shifting gradually to cool colors (red orange - yellow - green - light blue blue). Accordingly, it can be concluded that the movement potential in this area tends to range from a high to low level. Meanwhile, the social map shows that there are diverse social activities scattered in accordance with the area's integration value. That is, in the group of routes with a low integration value, there are activities requiring quiet, including residential, religious, learning and studying activities, etc. Along the routes with a high integration value, there are higher level activities requiring greater movement including a change of transportation mode activities, socializing, recreational activities, goods production, government contact, treatment and nursing activities, along with trade at Huaro Market. It can thus be concluded that the Huaro Market area sees a complete range of social activities in line with the area's integration value.
Pattern 2: This is an area in which the spatial model shows the transportation routes from communities in cool colors only (green - light blue - blue). Accordingly, it can be concluded that the movement potential in this area tends to be low. Meanwhile, the social map shows that the social activities are diverse, complete and scattered in the area along routes with a low integration value. In spite of this, there are higher level activities requiring greater movement, incompatible with the area's integration value, especially trade in the large commercial area of Chaophrom Market, along with transportation mode change activities, government contact activities and medical treatment activities. All these are activities at the town level requiring people to travel to this area. At the same time, there are activities requiring quiet such as residential activities, religious activities, educational activities, etc. So it can be concluded that in the Chaophrom area, a complete range of social activities occurs but not in accordance with the area's integration value. 
Pattern 3: This is an area in which the spatial model shows the transportation routes from communities from warm colors to cool colors (yellow - green light blue - blue). Accordingly, it can be concluded that the movement potential in this area tends to range from rather high to low levels. Meanwhile, the social map shows that diverse social activities are scattered in the area along various routes. In the group of routes with a low integration value, there are activities requiring quiet such as residential activities, religious activities, educational activities, etc., whereas along the routes with a rather high integration value, there are activities requiring high movement. These include change of transportation mode, government contact, goods production and trade (convenience stores) but the scale of these activities is not large enough for the area to become a market. This pattern appears in two areas: the Pratoochai area and part of the PakkranBaanpom area. (Note: Pratoochai, literally meaning 'gate of victory', was the major gate through which troops left for battles in the Ayutthaya period and is a symbol of victory and honor.) It can be concluded that this area does not see a wide range of social activities but the activities that do occur are in line with the integration value of the Pratoochai and Pakkran-Banpom areas.

Pattern 4: This is an area in which the spatial model shows the transportation routes from communities in cool colors (green - light blue - blue). Accordingly, it can be concluded that the movement potential in this area tends to range from low to very low levels. Meanwhile, the social map shows mostly residential activities and social activities, which are not high level activities occurring in the area. These include educational activities, goods production activities and religious activities. There may be some trade but on a small scale in the community. This pattern appears in the area which was formerly an alcohol distillery, referred to in Thai as Rongngansura. It can thus be concluded that in this Rongngansura area, social activities that occur do not encompass a wide range but they are in accordance with the integration value of the area.

The spatial features and social, cultural and economic activities are related in four ways and can be divided into five areas as shown in Figure 10.

\section{The nature of communities in Ayutthaya Historic Town}

The analysis results, in the earlier stage, reflect the nature of communities based on the level of activities in five areas reflecting four patterns. At this stage, the analysis is presented in greater detail to point out the patterns of relationships that various community groups have with each other and the relationships that they have in regards to the town system as a whole which contribute to the existence of these communities. Each group area is described in detail below. The five areas are the Huaro Market community group area, the Pratoochai community group area, the Pakkran-Banpom community group area, the Chaophrom market community group area and the Rongngansura community group area. 


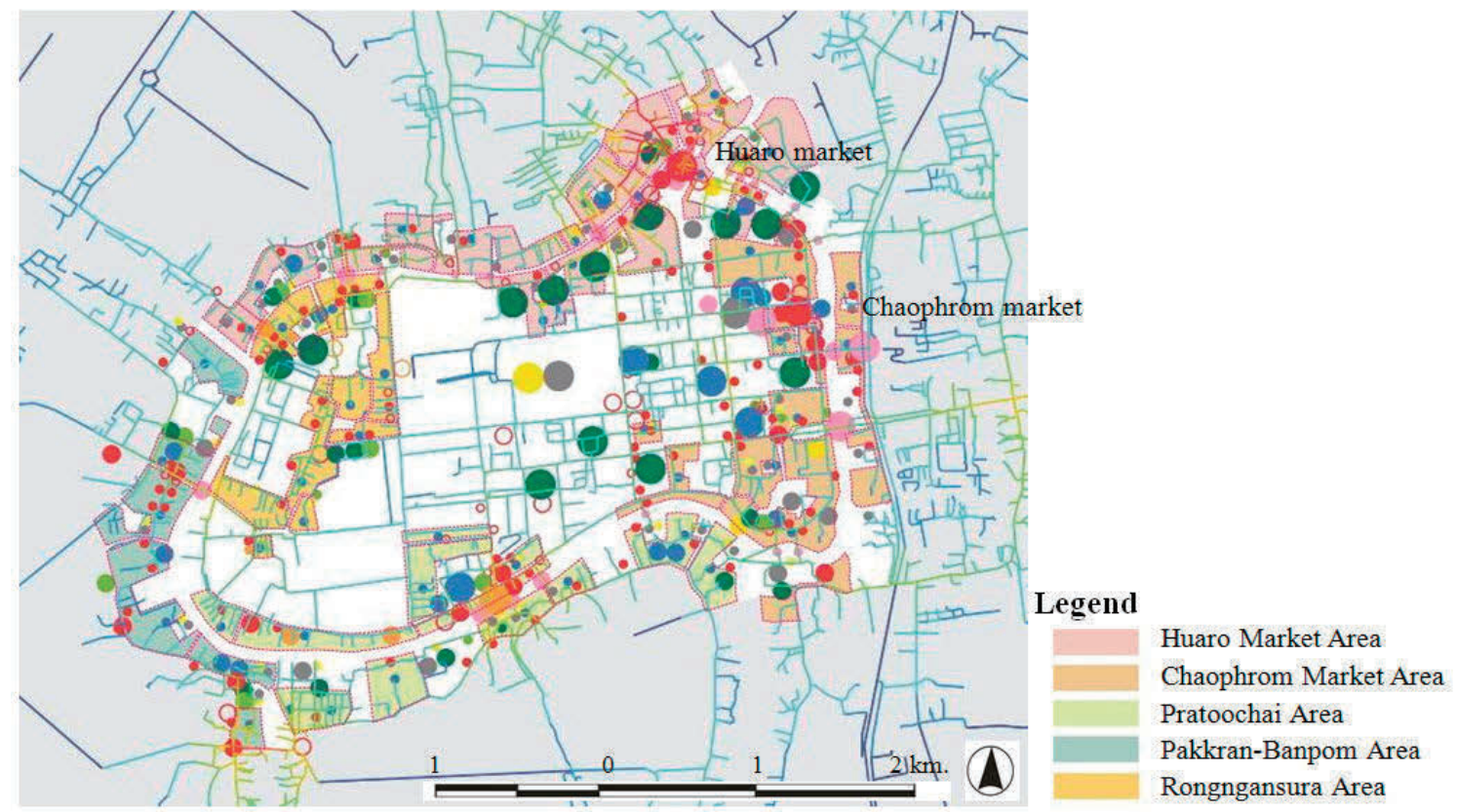

Figure 10: The spatial feature of the socio-economic activities of the community in four patterns

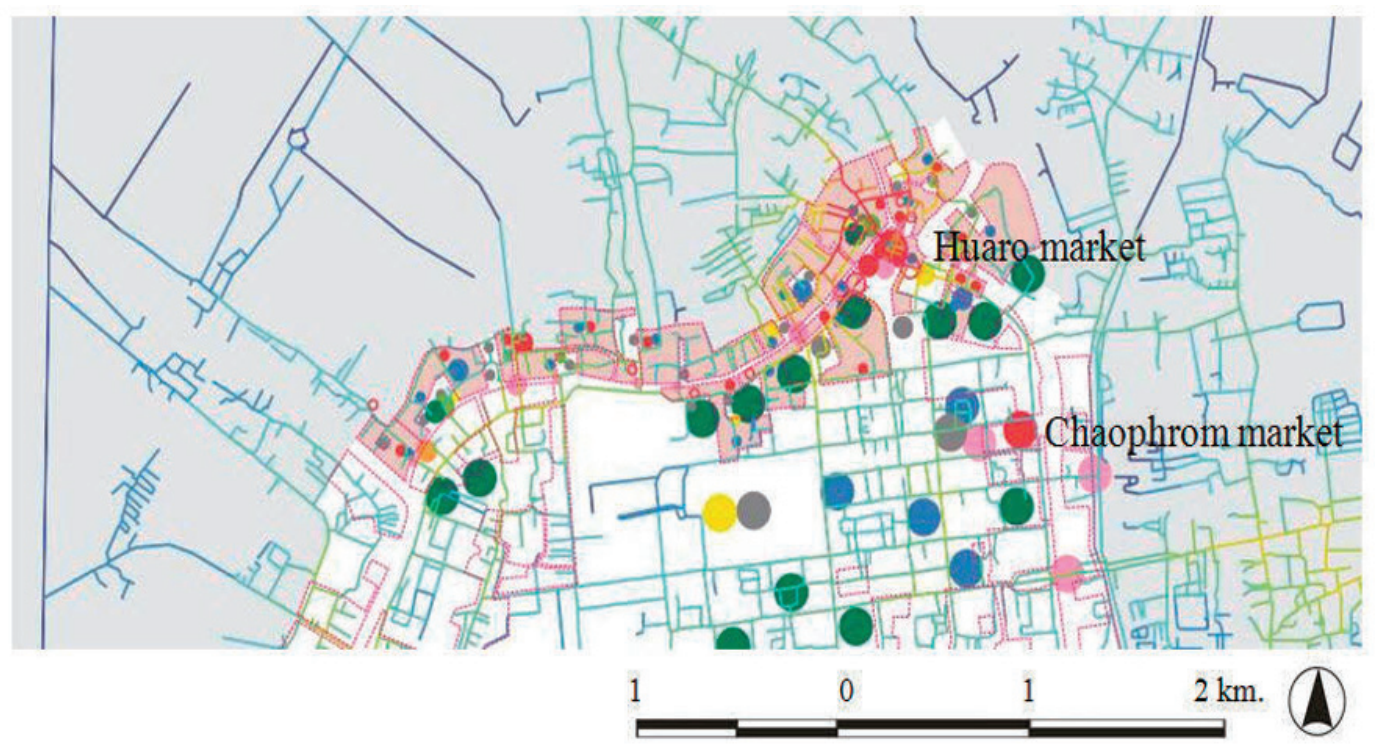

Figure 11: Spatial configuration network and social map of Huaro Market community group 


\section{Group 1: The Huaro Market community group area}

According to the spatial analysis results of the Huaro Market community group area, as shown in Figure 11, the transportation network features several types of road. The communities on both banks of the town canal are thoroughly and wellconnected by bridges and piers. People can therefore meet and socialize, resulting in various levels of movement and people circulating freely - both those living in the community and visitors. In the area within this group with a concentrated transportation network, there is a high integration value with surrounding areas allowing for significant freedom of movement. This area has thus developed into a lively town center and attracts continuous trade with occasional markets, all-night markets and related activities. The areas in the group that have low integration values have few people and support mainly residences and handicraft production, etc. along with temples, schools, government offices, etc. These comprise a complete set of elements of a community, enabling people to stay primarily within their community group.

Regarding the socio-economic characteristics of people in this community group, many people are relatives or neighbors and so they know each other well and they live under certain social rules informally established through mutual dependence. An example of this is the use of public space and transportation areas for personal activities. As a result, these people often have the opportunity of meeting and visiting each other and in turn, become close and build trust, fostering a network and diverse socioeconomic activities within the community and between communities. Some activities are temporary while others become recurring, such as certain ceremonies or traditional fairs, which help residents earn income by way of traditional knowledge, especially for activities related to historical structures or sacred entities. Such activities have a major role in ensuring that people throughout the community and visitors alike are respectful to the area. This also contributes to the care and maintenance of the historic town's resources. In addition, most trade in the market revolves around consumer goods which convey a traditional image, complementing the identity of the community group (Figure 12).

External factors, namely technology and innovation, contribute to the well-being of people in the community. Governmental plans and policies also serve as a mechanism to ensure that the transportation network is efficiently developed and connected. It can therefore be concluded that the Huaro Market community group area has spatial characteristics in line with the socioeconomic features of a complete community which enable it to fully function within its own community group. 

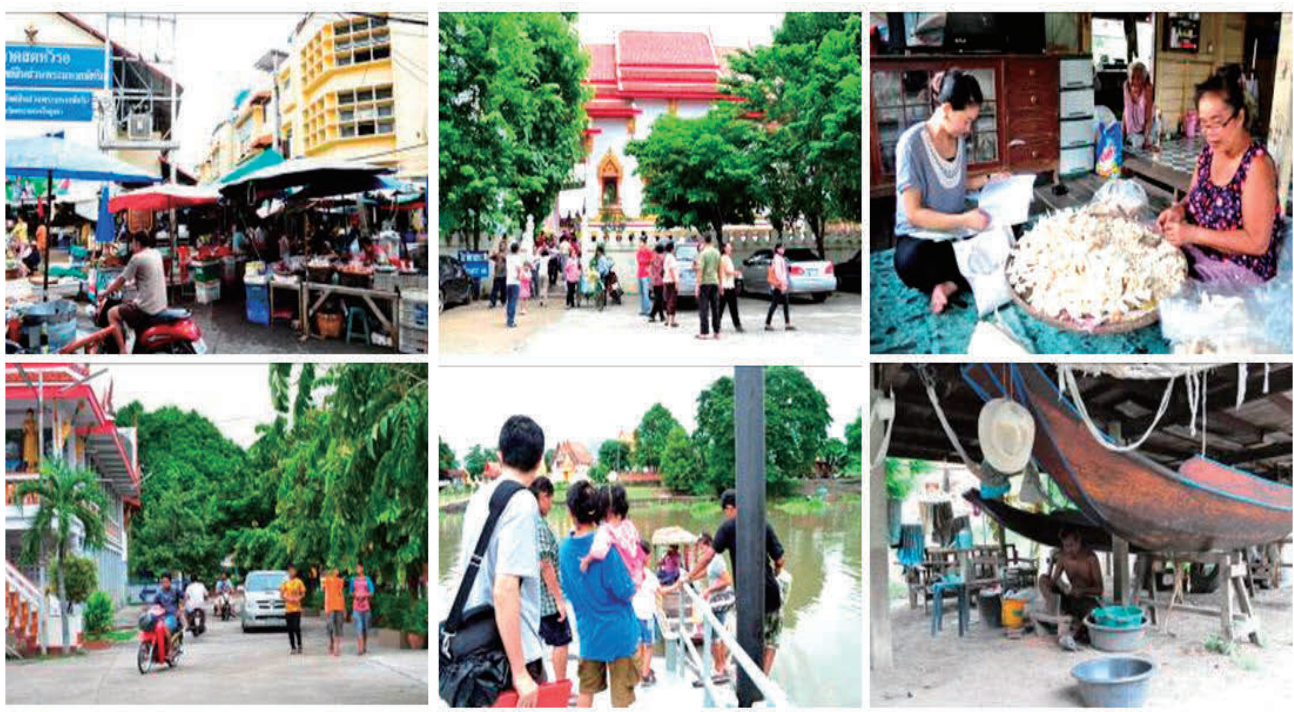

Figure 12: Activities in the Huaro market community group

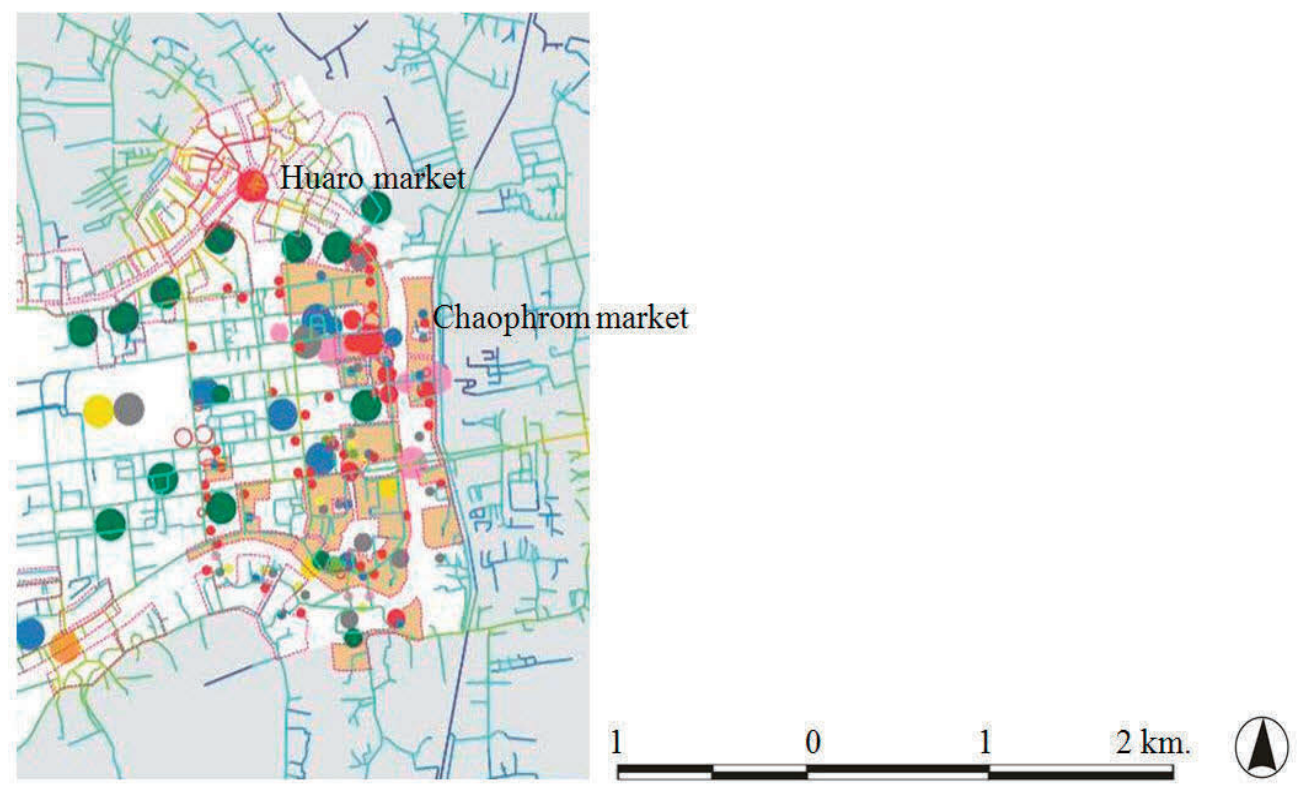

Figure 13: Spatial configuration network and social map of the Chaophrom Market community group 


\section{Group 2: The Chaophrom Market community group area}

The spatial analysis results for this community group area, as shown in Figure 13 reveal that the transportation network features only main roads and minor roads that support transportation at the town level. Routes for people in the community are spaces between shophouse buildings or houses and sidestreets and sidewalks. Therefore, many people walk or ride motorcycles as well as driving larger vehicles. This is not very conducive to social interaction. Also, as land transportation has become more popular, the Pasak River, which has traditionally been used for transportation, now segregates the communities on the two river banks. This is in spite of the large bridges and ferry piers in place for crossing the river which are capable of handling large numbers of people. The transportation route network on the whole, however, is thus not well interconnected and does not enhance the circulation of people at all times. In the area there is the Chaophrom Market, where trade serves as a draw for of other activities. There are also facilities supporting tourism such as hotels and restaurants, etc., which help bring together elements of the community and allow people to conduct important activities within their community group. However, this commercial area does not have a connectivity of routes that favors continuous activity and freedom of movement. Therefore, when there is trade in the market, when people take the ferry during government office hours or the rush hour or when there is a festival that brings in visitors, the area has traffic congestion problems. At other times, it is often deserted.
Regarding the socio-economic characteristics of people in this community group, there are both natives of the area and those who have relocated for various purposes including to work, travel, study and shop. These two groups generally do not interact socially with each other. As a result, people do not create a network and participate together in socio-economic activities at the community level. Because of this, the community has few longstanding ceremonies or traditions. On the other hand, there are annual festivals arranged by the government at the town level. These include the Songkran Festival, Chinese New Year, etc. Community leaders and some community members take part in these activities while others participate only as traders or tourists (Figure 14).

External factors, namely governmental plans and policies, have significantly contributed to the fact that private land ownership in this area is permitted. People are also permitted to use buildings and land more freely. As a result, activities are dense and diverse. Technology and innovation also contribute to the wellbeing of the people although the transportation network in the area is not very efficient. It can be concluded that the Chaophrom Market community group area does not have spatial characteristics in line with its socio-economic features. Activities that occur are the result of the socio-economic factors of its "attractors". These have led to the community having the elements of a complete community which enables it to function. 

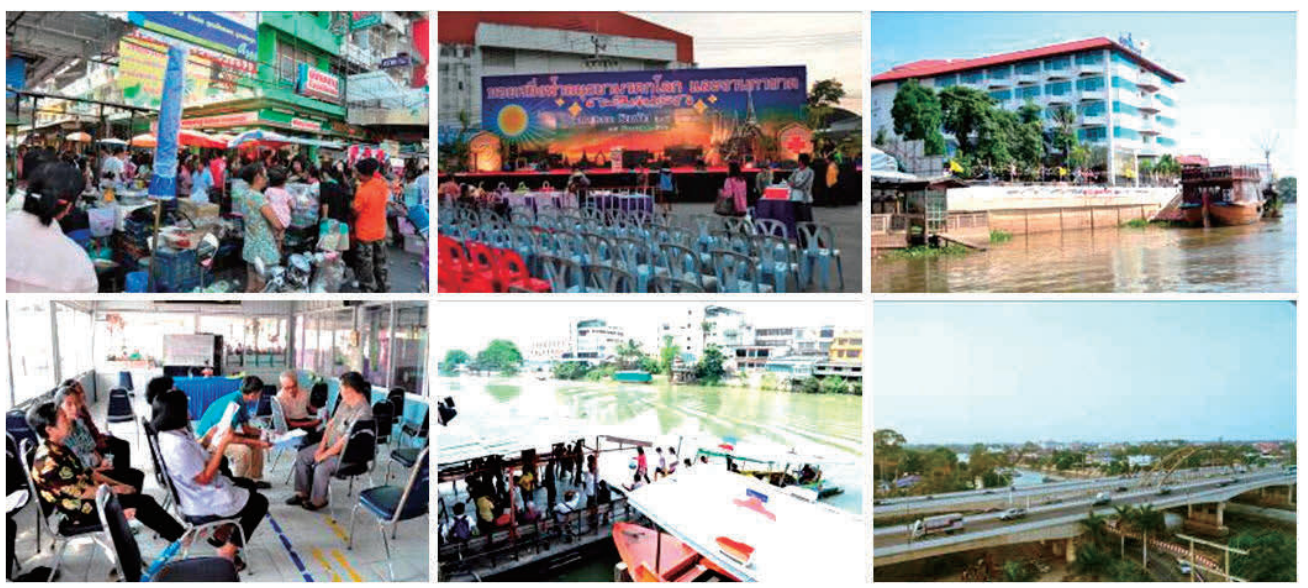

Figure 14: Activities in the Chaophrom Market community group

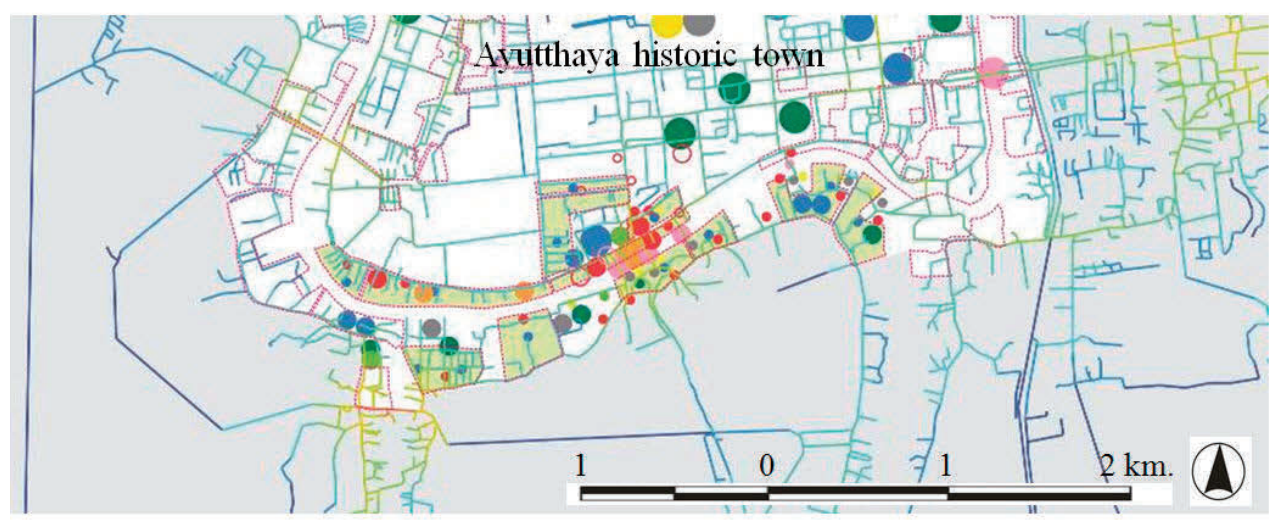

Figure 15: Spatial configuration network and social map of the Pratoochai community group
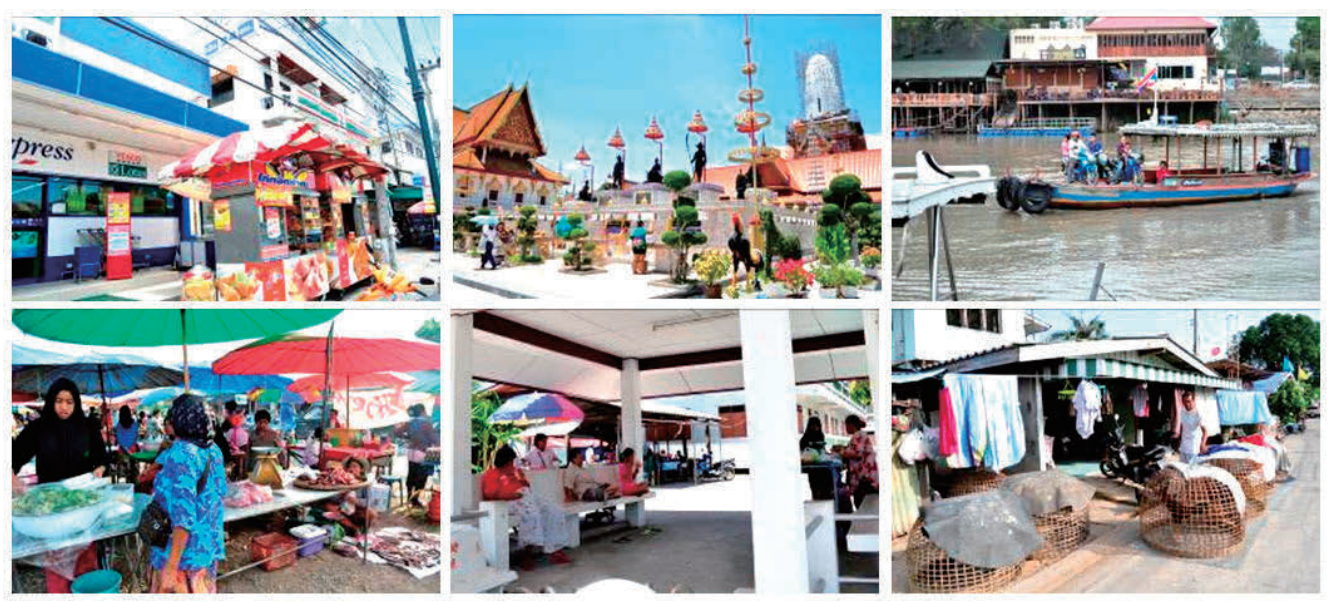

Figure 16: Activities in the Pratoochai community group 


\section{Group 3: The Pratoochai community group area}

The spatial analysis results of this community group area, as shown in Figure 15 , reveal that the transportation network features roads of different sizes and water transportation routes as well as pedestrian routes that have formed informally on temple grounds, school grounds, riverside areas, between buildings, etc.

Communities along both banks of the Chaophraya River are connected by a ferryboat and are easily accessible. This promotes the circulation of people on foot or in small vehicles. However, this is concentrated in the community's inner area and the riverfront area near the piers. Further out are minor roads and smaller roads on which larger vehicles travel quickly to other areas. Because of this, although the transportation network in general has spread throughout the area, it is not interconnected enough to create a high integration value to allow for a market and, thus, the area is residential with religious structures (temples, mosques, and shrines), retail shops, schools, handicraft production centers, government offices, hospitals, sports grounds and recreational areas. These add to people being able to live within the community group, but require them to go shopping at Huaro Market or Chaophrom Market.

Regarding the socio-economic characteristics of people in this community group, many people are relatives or neighbors and those with the same religious beliefs live in the same community, be they Christians, Buddhists or Muslims. This community group clearly reflects different ethnic and religious features and each community is mutually dependent and under the same informally set social rules. One example of this is the use of public space and transportation areas for personal activities. As a result of this, they often have the opportunity to meet and visit and, in turn, become close and trust each other, fostering a network of diverse socio-economic activities within the community and between communities. Some activities are temporary or become regular, such as religious ceremonies or traditional fairs, helping those involved to earn a living based on traditional knowledge. But these activities and the network that has developed appear only in the community and are less related to historical structures than those of the Huaro Market community group. On the other hand, whatever faith the people in the community practice, they practice it devoutly and together, requiring visiting outsiders to be respectful of the area and the people there, which has significantly helped the community to maintain its identity.

External factors, namely technology and innovation, contribute to the well-being of people in the community group. Governmental plans and policies also serve as a mechanism to ensure that the transportation network is developed and efficiently connected while allowing the community to maintain its distinct characteristics. It can be concluded that the Pratoochai community group area has spatial characteristics in line with its socio-economic features but does not have all the elements necessary to be a selfreliant community. This requires that the inhabitants occasionally depend on other communities in order to function. 


\section{Group 4: Pakkran-Banpom community group area}

The spatial analysis results of this community group area as shown in Figure 17 reveal a transportation network of roads of different sizes as well as pedestrian routes that have formed informally. This has promoted the circulation of people either on foot or in small vehicles. However, this is centered in the community's inner area and on the riverfront area near the piers. Further out are minor roads and smaller roads where larger vehicles travel quickly to other areas. Although the transportation network in general has spread throughout the area, it is not concentrated enough to create an area with a high enough integration value to become a lively market area. However, as this community group is located far away from the town's commercial area (Huaro Market and Chaophrom Market), temporary trading spaces have developed in the form of occasional markets. There are also religious structures, retail shops, schools, government offices, medical centers, sports and recreational facilities. These add to the elements of a community enabling people to largely live within the community group; however, they do need to go shopping for certain goods at Huaro Market and Chaophrom Market.

Regarding the socio-economic characteristics of people in this community group, like those in the Pratoochai community group, many people are either relatives or neighbors. Their way of life and social rules are informal and result from their mutual trust, which has led to the development of networks of socioeconomic activities. Some activities are temporary or have become regular occurrences but they tend to be in the community only and are not really related to historical structures or sacred entities of the historic town. On the other hand, whatever religion people in the community practice is shared and taken seriously. This has significantly helped the community maintain its distinct identity.

External factors, namely technology and innovation, contribute to the well-being of people and governmental plans and policies also serve to ensure a transportation network that is sufficient and interconnected both within the community and with the town area. It can therefore be concluded that the PakkranBanpom community group area has spatial characteristics in line with its socio-economic features but lacks certain elements of a community which requires that inhabitants occasionally depend on other communities to function. 


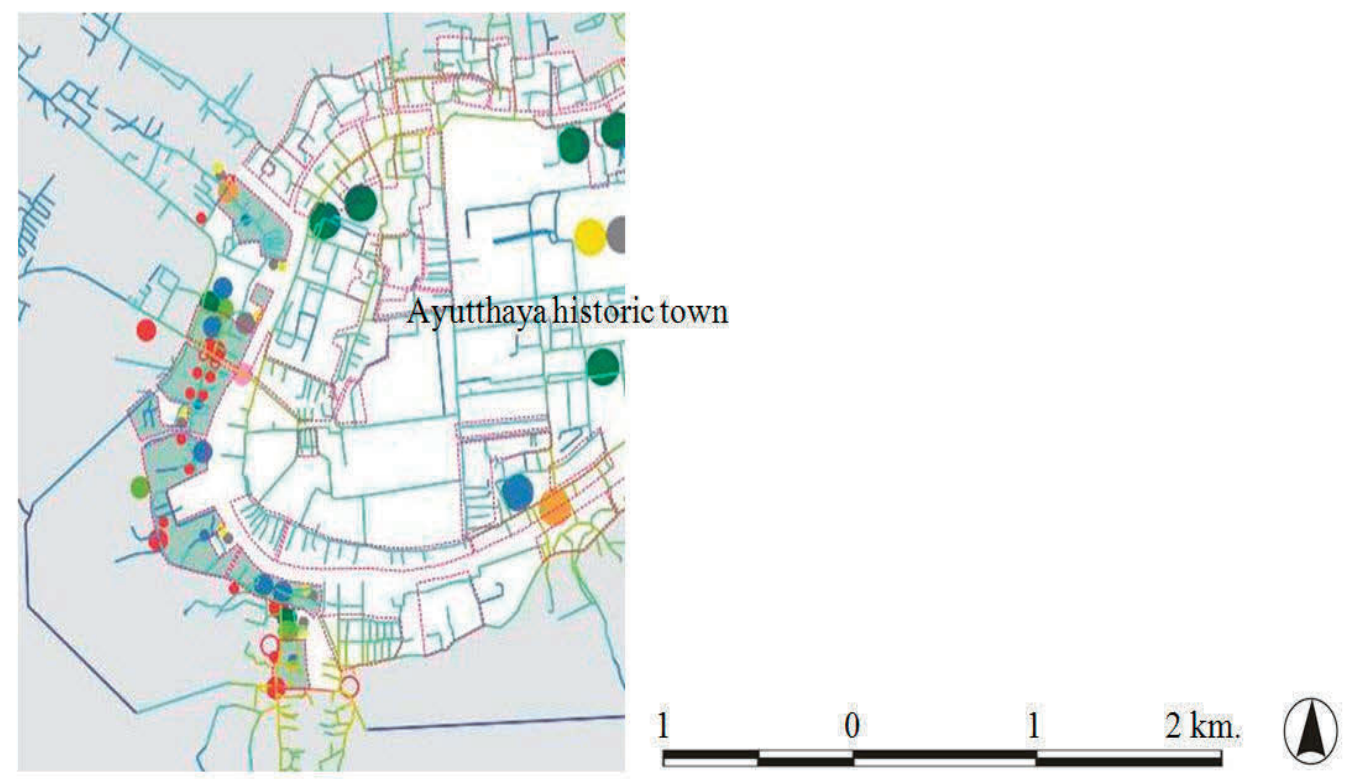

Figure 17: Pakkran-Banpom community group
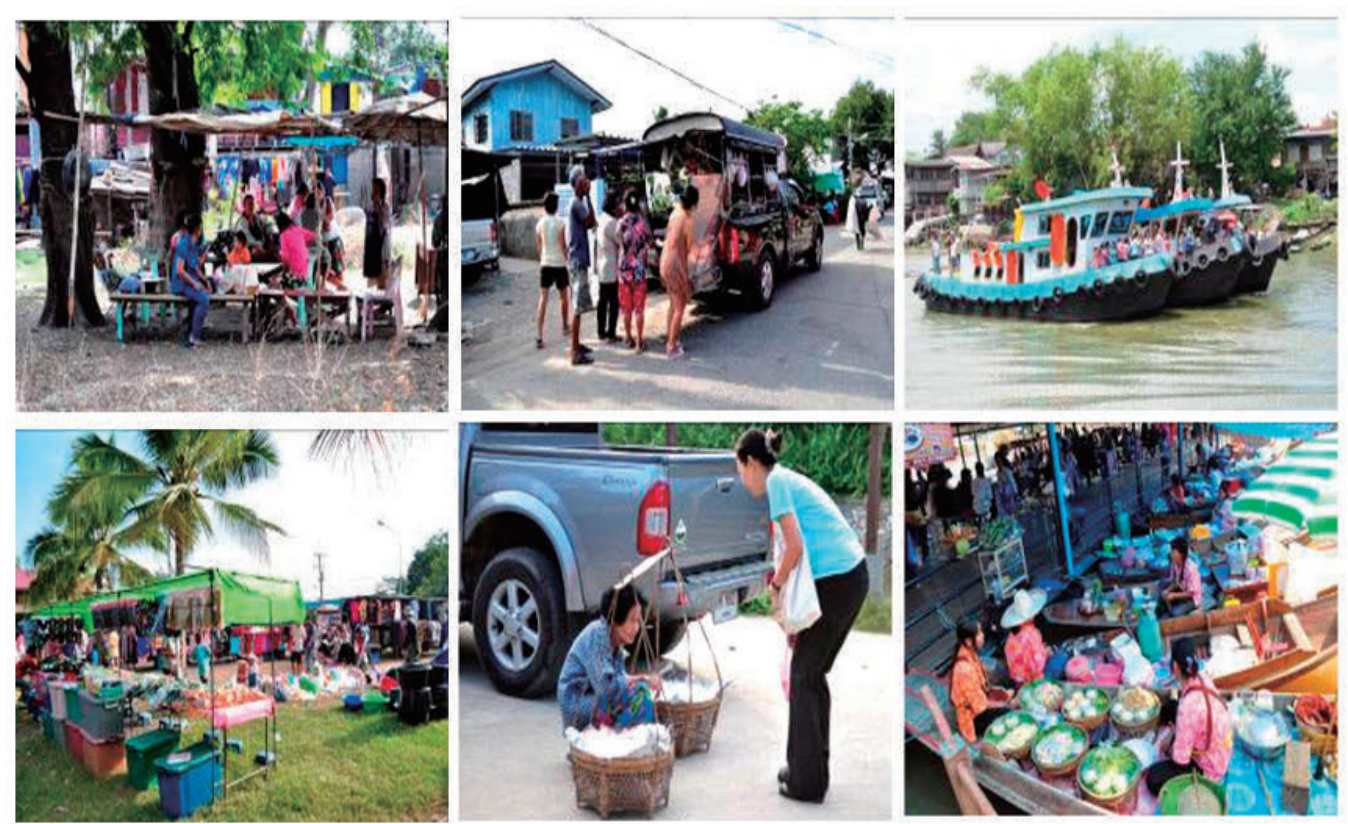

Figure 18: Activities in the Pakkran-Banpom community group 


\section{Group 5: The Rongngansura community group area}

The spatial analysis results of this community group area, as shown in Figure 16 , reveal that the transportation network features the town's main roads connecting with the entrances to the area of this community group. In the community itself most roads are short and narrow and go directly to the houses. As this community group area is bordered by the Chaophraya River, the ancient canal, a lowland flood plain and the historical park area, the community area is of a smaller size than the other groups. Transportation routes are also few and interspersed. Moreover, within the community group there are dilapidated houses, houses of government officials who once worked for the alcohol distillery and houses of people relocated from elsewhere. The transportation network on the whole is not fully or systematically connected and, in turn, does not promote the circulation of people in the area. It was found that only residents of the community travelled in the area. Therefore, unlike the other community groups, there was a lack of variety in the activities conducted there. Buildings included only residences, schools and old temples. In addition, activities took place only in small spaces or along walkways in the community. People in this community group thus cannot exist solely within the group and need to do other necessary activities outside both near and far, especially when they need to go shopping, which is done at Huaro Market or Chaophrom Market.

The socio-economic characteristics of people within this community group indicate that the community is comprised of many types of people, so there are both people who know each other well and those who are strangers to each other. Their way of living is thus mutually dependent and they are related as necessity dictates within social rules set both formally and informally. Being relocated results in people feeling insecure and the network of socio-economic activities, in general, is thus important to survival. Some people like to carry on certain traditional or religious activities especially those with which they are familiar with or those that were carried out by their ancestors who lived outside this community area. As a result, people in this community group have almost no shared traditions or knowledge that were practiced together in the old days.

External factors, namely governmental plans and policies, significantly contribute to the area's development in terms of public utilities and housing management as well as budget support for public health, education, occupations, etc. Community leaders are the representatives regarding policies and budget support from the government for community development to upgrade living standards. Technology and innovation also help provide comfort and convenience. In spite of the limited space, people can continue to live in the community while travelling to other communities both near and far for certain needs. It can be concluded that the Rongngansura community group area has spatial characteristics in line with its socio-economic features but without all the necessary elements of a self-reliant community. This requires that people often depend on various other communities in order to conduct some necessary activities. 


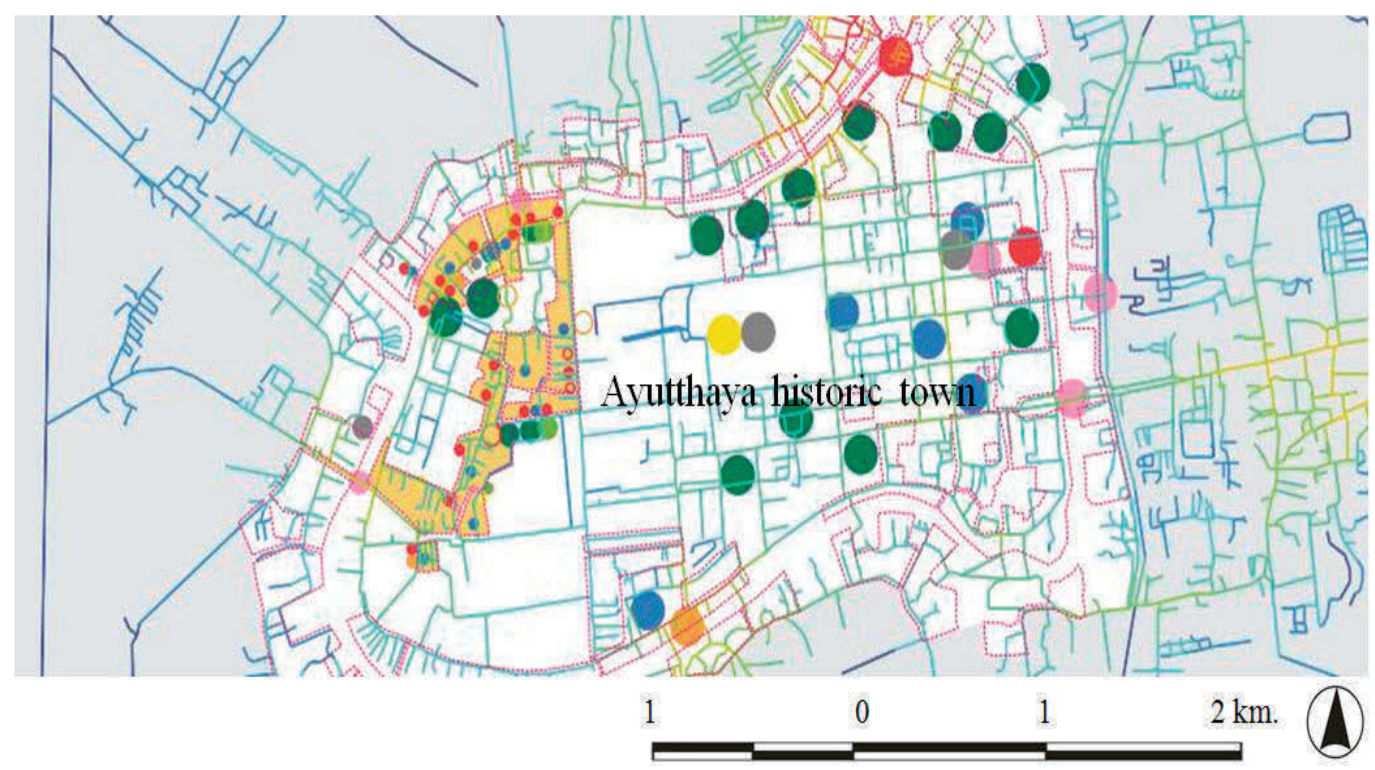

Figure 19: the Rongngansura community group
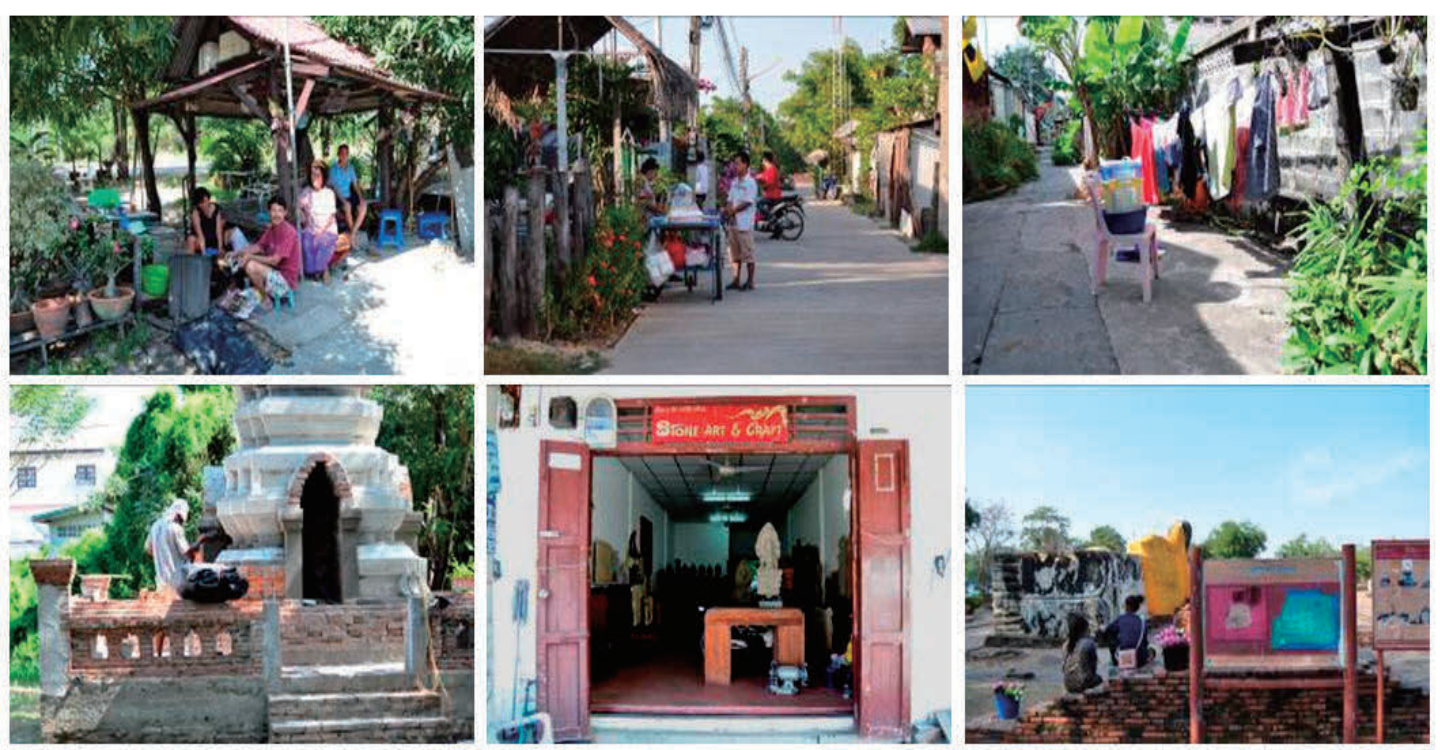

Figure 20: Activities in the Rongngansura community 


\section{Discussion and Conclusion}

The study results show that the communities in the Historic Town of Phra Nakorn Sri Ayutthaya have adopted a system of mutual dependence with other communities both near and far and can be classified into five community groups, namely the Huaro Market community group, the Pratoochai community group, the Pakkran-Banpom community group, the Chaophrom Market community group and Rongngansura community group. These groups can be further subdivided into three types based on patterns of activity: 1) Groups with complete elements enabling them to exist solely within the group, namely the Huaro Market community group and Chaophrom Market community group. 2) Groups with incomplete elements that have to rely on other communities occasionally, namely the Pratoochai community group and the Pakkran-Banpom community group. 3) Groups with incomplete elements that always have to rely on other communities, both near and far, namely the Rongngansura community group.

The Huaro Market community group situation is the result of transportation network factors. The network is efficiently connected in accordance with the concept of spatiality as a process, which is an important condition for the existence of communities and the result of desirable morphological characteristics. In the case of the Chaophrom Market community group, it was found that the community is able to exist due to its network and the socio-economic activities which serve as attractors for trade and other activities, regardless of the integration value of the area. In the case of the Pratoochai community group and the PakkranBanpom community group, they are able to continue due to the transportation network combined with socio-economic activities. However, they lack some elements that would allow them to function solely within their group. This is also the case with the Rongngansura community group, for which external factors such as governmental plans and policies as well as locality plans largely enable the group to continue to exist, albeit with reliance upon other communities.

Based on the research findings, the following policy recommendations are made so that each community group can continue to exist in the historic town while maintaining its own identity.

The Huaro market community group has the potential for development as a residential-cum-commercial community and as a site for 'local' historical tourism. This is because the people already live a traditional lifestyle in the community. Suggestions include sightseeing boat cruises, the production of handicraft goods, freshwater fishing, riverside homestays, shopping at the night market, etc. Huaro Market can be designated as a market focusing on the sale of consumer goods and traditional activities to distinguish itself from other markets. In addition, in the development of the transportation network in the future, current routes should be maintained to support the people's way of life and the network of activities.

The Chaophrom market community group area has the potential for development as a residential-cum-commercial community and as a point for a change of transportation mode activities at the town level. It should emphasize historical tourism as part of the 'urban life style' as there are already related facilities such as 
hotels, other temporary lodgings, riverside restaurants, as well as sightseeing trips by tuk-tuk or by boat, etc. In addition, regarding the development of the transportation network in the future, current routes should be maintained and those used in the past, including both land and water routes, should be reactivated, which would promote a diversity of transportation modes. The riverside area should also be opened up so people in the community and visitors alike can use the space together. In addition, networks and social activities that have disappeared, particularly those activities related to historical structures in the area, should also to be rehabilitated or revived so that people see more value in the structures than is the case at present.

The Pratoochai community group area and the Pakkran-Banpom community group area have the potential for development as residential communities with historical tourism showcasing the cultural diversity of the people living along the river. For example, there could be a boat trip to see how people live and to view the architecture in various communities. There could also be conservation tourism for festivals and then at other times the area could continue as a quiet residential community. Commerce in this area could focus on production and the sale of gift items, especially local foods, which must be bought and sold easily and quickly due to limitations in terms of parking. In addition, regarding the development of the transportation network in the future, current routes should be maintained while adding piers or bridges to enhance diversity in modes of transportation which will reduce car traffic. The networks and the activities already existing in the community should be supported so that they continue into the future.

The Rongngansura community group area has the potential for development as a residential-cum-commercial community with historical tourism showcasing the 'old capital lifestyle.' For example, it could be a village of craftspeople involved in the production and sale of handicraft goods or souvenirs. As for the lowland flooding area, it could be dredged to retain water and a floating market could be established. This could also support a village of houseboats to enhance the identity of the community as well as to create jobs for its people. Emphasis should be placed on those occupations involving the production and sale of handicraft goods that encourage customers to linger and browse. This would improve tourist circulation within the community and raise living standards. In addition, the transportation network should be enhanced the in future by creating or rehabilitating walking routes, shortcuts, open areas, ancient canals and connecting points like piers and bridges. Part of the area of historical structures and the historical park should be open for community access so that the whole system can be interconnected.

These recommendations are based on the particular characteristics of each community group so that the various communities in Historic Ayutthaya Town area can continue to exist in a proper town context with spatiality which supports them socially, culturally and economically in the present and future, whilst allowing them to retain their own distinct identity.

These findings also support the use of spatial centrality as a process theory which holds that the connection of efficient 
transportation networks in a city affects the people's tendency to access an area and the diversity of activities conducted within it. Potentially high visibility areas are likely to have more intense activity than other areas, especially for business. These other areas are generally for living and other connected activities. Therefore, the key factor for the existence of the community in the historic town is to preserve, reinforce and restore the transportation networks between the community and the historic area so that they are systematically and appropriately united. This will allow people greater access to the area and promote a diversity of activities resulting in complete community living in an area with a distinct identity.

\section{Acknowledgements}

This article is a part of a Ph.D. dissertation entitled, "Spatial Conditions for Existence of Communities in and around Ayutthaya Historic Island" submitted to the Department of Urban and Regional Planning, Faculty of Architecture, Chulalongkorn University. The author would like to thank The Office of Higher Education Commission for providing the "Teacher Development Scholarships" for Ph.D. studies.

\section{References}

Hillier, Bill et al. 1993. Natural movement: or, configuration and attraction in urban pedestrian movement. Environment \& Planning B: Planning \& Design. 20: 29-66

Hillier, Bill. 1996. City As Movement Economics. Cambridge University Press, London.
---. 2000. Centrality as a Process: Accounting for Attraction Inequalities in Deformed Grids. Paper presented at The $2^{\text {nd }}$ International Space Syntax Symposium Proceedings Volume II, March/April, 1999. Brazil

Hillier, Bill and Julienne Handson. 1984. The Social Logic of Space. United Kingdom: Cambridge University.

Jacobs, Jane. 1961. The Death and Life of Great American Cities. London : Penguin.

Kasetsiri, Charnvit. 2007. Ayutthaya: Discovering Ayutthaya (อยุธยา:

Discovering Ayutthaya). Bangkok: The Foundation for the Promotion of Social Science and Humanities Textbooks Project (มูลนิธิโครงการตำราสังคมศาสตร์ และมนุษยศาสตร์). (In Thai)

Khanjanusathiti, Pinraj. 2009. Conservation of architectural heritage and community (การอนุรักษ์มรด สถาปัตยกรรมและชุมชน). Bangkok: Chulalongkorn University. (In Thai)

Phatumanonta, Thipsuda. 2000. Architecture Kangsadarn of thought (สถาปัตยกรรม กังสดาลแห่งความคิด).

Bangkok: Chulalongkorn University. (In Thai)

Satyawadhna, Cholthira et al. 2004. Community rights of the Ban Khrua community in Bangkok and the social aspects of the effect of building express highway (สิทธิชุมชนท้องถิ่นบ้า ครัว กรณี การสร้างทางค่วนทับชุมชน). Bangkok: Nititham. (In Thai) 
Smailes, Arthur E. 1966. The Geographic of Towns. Hutchinson University Library. Hutchinson.

Suwan-Achariya, Chinasak. 2006. Social

Networks (เครือข่ายทางสังคม).

Mahasarakham : mahasarakham university. (In Thai)

Tangsiriwanit, Thawatchai. 2006. Ayuthaya kingdom on the map of France (กรุงศรีอยุธยาในแผนที่ฝรั่ง). Bangkok: Matichon. (In Thai)

The Fine Arts Department. 1997. A Development of Master Plan in Ayutthaya Historical Town Project (ครงการปรับปรุงแผนแม่บทนครประวัติศาสตร์ พระนครศรีอยุธยา). Bangkok: NSP Printing Group. (In Thai)

Tuner, Alasdair et al. 2005. An algorithmic definition of the axial map. Environment and Planning B: Planning and Design. 32: 425-444. 